\title{
HAEMATOCOCCUS PLUVIALIS MODULATING EFFECT ON NEUROTRANSMITTERS, HORMONES AND OXIDATIVE DAMAGE-ASSOCIATED WITH ALZHEIMER'S DISEASE IN EXPERIMENTAL RAT'S MODEL
}

\author{
FAROUK K. EL-BAZ ${ }^{*}$, HANAN F. ALY2 ${ }^{2}$, GAMILA H. ALI ${ }^{3}$
}

${ }_{1}^{1}$ Plant Biochemistry Department, National Research Centre (NRC), 33 El Bohouth st. (former El Tahrir st.), Dokki, Giza, Egypt, P. 0.12622, ${ }^{2}$ Therapeutic Chemistry Department, National Research Centre (NRC), 33 El Bohouth st. (former El Tahrir st.), Dokki, Giza, Egypt, P. 0.12622, ${ }^{3}$ Water Pollution Research Department, National Research Centre (NRC), 33 El Bohouth st. (Former El Tahrir st.), Dokki, Giza, Egypt, P. 0.12622

Email: fa_elbaz@hotmail.com

Received: 20 Oct 2016 Revised and Accepted: 21 Dec 2016

\section{ABSTRACT}

Objective: This study was planned to assess the efficacy of Haematococcus pluvialis in the regression of Alzheimer's disease (AD).

Methods: Fifty rats were divided into five groups. Positive control group orally received aluminium chloride in a dose $100 \mathrm{mg} / \mathrm{kg}$ to induce AD: AD induced rats were orally treated with $H$. pluvialis extract $(150 \mathrm{mg} / \mathrm{kg})$ and rivastigmine standard drug ( $4.6 \mathrm{mg} / \mathrm{kg} /$ day) for $30 \mathrm{~d}$. Brain acetylcholine esterase (AchE), acetylcholine (Ach), dopamine (DA), adrenaline (A), noradrenaline (NA), oxidative stress biomarkers and superoxide dismutase (SOD) were determined. Further, adrenocorticotropic hormone (ACTH) and cortisol (CORT) levels were evaluated. Also, brain histopathological investigation was examined.

Results: AD induced rats recorded a significant increase in the brain AchE, concomitant with a significant decrease in Ach, DA, NA, A and SOD levels. While, a significant increase in $\mathrm{NO}$ and $\mathrm{H}_{2} \mathrm{O}_{2}$, CORT and ACTH was recorded. Moreover, brain histopathological investigation in AD rats showed the formation of amyloid plaques and necrosis of neurons. Treatment of $\mathrm{AD}$ induced rats with extract of $H$. pluvialis or standard drug resulted in an improvement in the most of the all studied biochemical parameters. Also, AD groups treated with extract or standard drug showed great improvement in the brain morphological structure with normalisation of cerebral cortex and hippocampus, though, necrosis of some cerebral neurones was detected.

Conclusion: This current study indicated that $H$. pluvialis extract and drug significantly ameliorates the neurotransmitters level, oxidative damage as well as pituitary function due to their anticholinesterase activity, antioxidant efficacy, beside the anti-inflammatory effect.

Keywords: Alzheimer's disease, Haematoccus pluvialis, Anticholinesterase, neurotransmitters, Oxidative stress, Pituitary function, Neuroinflammation, Apoptosis

(c) 2017 The Authors. Published by Innovare Academic Sciences Pvt Ltd. This is an open access article under the CC BY license (http://creativecommons.org/licenses/by/4. 0/) DOI: http://dx.doi.org/10.22159/ijpps.2017v9i2.15797

\section{INTRODUCTION}

The most well-known type of neurodegenerative dementia in elderly is Alzheimer's disease (AD) which approximately $60 \%$ of patients with dementia [1]. $\mathrm{AD}$ is a disease that affects memory, thought, reasoning and language as well as serious cognitive disability and death of nerve cells. Memory is an organism's mental ability to store, retain and recall information. Pathologically, $\mathrm{AD}$ is characterised by senile plaques due to abnormal accumulation of extracellular amyloid $\beta(\mathrm{A} \beta)$ and the intracellular neurofibrillary tangles (NFTs) which are responsible for the neuronal loss, degeneration of cholinergic system [1], oxidative damage, synaptic dysfunction and inflammation [1]. The major risk factors for $\mathrm{AD}$ are advancing age, cardiovascular diseases, diabetes; obesity, cancer, low educational levels, head trauma and exposure to heavy metals such as aluminium (Al), cupper, iron and zinc [2]. Al has neurotoxic effect by many mechanisms; promoting formation and accumulation of senile plaques and neurofibirally tangles leading to progressive neuronal degeneration and death [3]. Cerebral inflammation, as well as systemic immunological alterations, has been reported in the pathogenesis of AD [1].

Epidemiological and pathological studies suggested a role for aluminum in neurological disorders like Alzheimer's and Parkinson's diseases [4]. Therefore, aluminum-induced biochemical changes that lead to behaviour and pathological disorders have become more interesting for researchers [4]. A number of enzymes and pathways have been introduced as aluminum targets based on its biological effects on the central nervous system [4]. In extrapyramidal motor activity disorders such as Parkinson's disease, dopamine and norepinephrine concentrations and also activity levels of their synthesising enzymes decrease in basal ganglia and some other regions of the brain like hypothalamus. In addition, the levels of copper ions are higher than zinc in brain and plasma of these patients [4]. It is suggested that alteration in catecholamine concentrations is responsible for neurological symptoms in this type of disorders [5]. On the other hand, concentrations of catecholamine are mostly regulated by the activity levels of their synthesising enzymes. One such enzyme is dopamine $\beta$-hydroxylase that catalyzes the final stage of norepinephrine synthesis from dopamine in the both medulla vesicles of the adrenal glands and synaptic vesicles of the noradrenergic neurological system [5].

Dopamine is one of the most important catecholamine neurotransmitters in the mammalian central nervous system. Several important diseases of the nervous system are associated with dysfunctions of the dopamine system [4]

It was evidenced that the increased secretion of glucocorticoids and/or prolonged exposure to hypercortisolism can damage the hippocampal neurones [6]. The hippocampus is the site of early pathological lesions of AD. This brain region, critical for memory performance, mediates the inhibition of glucocorticoid secretion arising at the end of the stress. Since hyperactivity of the hypothalamic-pituitary-adrenal (HPA) axis has been described in AD patients' [7], hippocampal degeneration has been proposed as either the cause or the effect of HPA hyperactivity. Adrenal hyperactivity in $\mathrm{AD}$ patients is not universally accepted, however, normal activity of HPA axis has been reported [7]. 
On the other hand, H. pluvialis is a common single-cell Chlorophyte algae species, found worldwide. A growing body of the scientific literature indicated that $H$. pluvialis species is well known for its high content of the strong antioxidant astaxanthin. Aastaxanthin is a more powerful antioxidant than other carotenoids and vitamin $\mathrm{E}$ and may confer numerous health benefits [8]. Further, astaxanthin, a powerful antioxidant, is a good candidate for the prevention of intracellular oxidative stress [9]. Animal and cell culture studies have also indicated that astaxanthin can be protective against several kinds of oxidative damage and may have beneficial health effects. These include protection from ultraviolet light-induced skin damage and certain cancers, amelioration of age-related macular degeneration, increased high-density lipoproteins (HDL) and decreased low-density lipoproteins (LDL), and enhancement of the immune system [10].

So, the present study was undertaken to declare the potential effect of $H$. pluvialis extract to modulate oxidative damage associated-AD in experimental rat's model.

\section{MATERIALS AND METHODS}

\section{Chemicals}

Rivastigmine, reagents and kits were purchased from Sigma Chemical Company (USA), while Aluminium chloride (CDH, India). TRIzol reagent was bought from Invitrogen (Germany). The reverse transcription and PCR kits were obtained from Fermentas (USA). SYBR Green Mix was purchased from Stratagene (USA).

\section{Cultivation of $\boldsymbol{H}$. pulivialis}

H. pluvialis (strain No. CCAP 34/7) was isolated by spreading $0.1 \mathrm{ml}$ of water samples collected from Nile River phytoplankton using BG11 media for algal isolation [9] into Petri dishes containing 1.5\% agar for solidification. Then, single colonies of algae were recultivated in the specified liquid media as non-axenic batch cultures (50 ml) at $25 \pm 2{ }^{\circ} \mathrm{C}$ and $24 \mathrm{~h}$ with continuous white fluorescent lamp intensity $\approx 2500$ Lux. Cultivation was carried out on an open pond with a capacity of $70 \mathrm{l}$ containing $55 \mathrm{l}$ of growth media. After cultivation, the biomass was initially separated from the water by gravitational settling and then further concentrated by centrifugation [10], then dried at $40^{\circ} \mathrm{C}$.

\section{Ethanolic extract preparation of $H$. pulivialis}

$100 \mathrm{~g}$ of $\mathrm{H}$. pluvialis powder was soaked in ethanol $(80 \%)$ and shacked on a shaker (Heidolph UNIMAX 2010) for $48 \mathrm{~h}$ at $150 \mathrm{rpm}$. The extract was filtered using a Buchner funnel and Whatman No. 4 filter paper and the algal residue was re-extracted with the addition of fresh ethanol for another two times. Combined filtrates were concentrated using Rotary evaporator (Heidolph-Germany) at $40{ }^{\circ} \mathrm{C}$ under vacuum. The resulting dry extract was evaporated on a rotary vacuum evaporator to dryness. The dry extract was stored at $-20^{\circ} \mathrm{C}$ in a freeze and kept for further analysis [11].

\section{Experiment}

\section{Animals}

Male Wistar rats (180-200 g) procured from Central Animal House; National Research Centre was used. Animals were acclimatized to the laboratory conditions at room temperature prior to the experimentation. Animals were kept under standard conditions of a $12 \mathrm{~h}$ light/dark cycle with food and water ad libitum in plastic cages with soft bedding. All the experiments were carried out between 9.00 and $15.00 \mathrm{~h}$. The study was approved by the NRC animal Ethical Committee Guidelines (approval no: 0112459) for the use and care of animals.

\section{Drugs and treatment schedule}

Aluminium chloride $(\mathrm{CDH}$, India) solutions were made freshly at the beginning of each experiment. For oral administration, aluminium chloride was dissolved in drinking water and administered in a dose of $100 \mathrm{mg} / \mathrm{kg}$, p. o. to rats daily for $6 \mathrm{w} 0.5 \mathrm{ml} / 100 \mathrm{~g}$ body weight [12].

Rivastigmine standard drug was daily administrated for one month in a dose $4.6 \mathrm{mg} / \mathrm{Kg}$ body weight [13]. Animals were randomised divided into five groups of ten rats each based on their body weight. Each group is having ten numbers of animals. The groups were as follows:

\section{Group one: Normal control rats}

Group two: Normal control rats treated with $H$. pluvialis ethanolic extract

Group three: Serving as AD rats, where rats were orally administered with aluminium chloride $\left(\mathrm{AlCl}_{3}\right)$.

Group four: AD rats treated orally daily with $H$. pluvialis ethanolic extract for $4 \mathrm{w}$ in a dose of $150 \mathrm{mg} / \mathrm{Kg}$ body weight [14].

Group five: AD rats orally treated daily for $4 \mathrm{w}$ with a standard drug.

\section{Brain tissue sampling and preparation}

At the end of the experiment, the rats were fasted overnight, subjected to anaesthesia with diethyl ether and sacrificed. The whole brain of each rat was rapidly dissected, washed with isotonic saline and dried on filter paper. Each brain was divided sagittal into two portions. The first portion was weighed and homogenised in icecold medium containing $50 \mathrm{mmol}$ Tris/ $\mathrm{HCl}$ and $300 \mathrm{mmol}$ sucrose at $\mathrm{pH} 7.4$ to give a $10 \%(\mathrm{w} / \mathrm{v})$ homogenate [14]. This homogenate was centrifuged at $1400 \times \mathrm{g}$ for $10 \mathrm{~min}$ at $4^{\circ} \mathrm{C}$. The supernatant was stored at $-80{ }^{\circ} \mathrm{C}$ and used for biochemical analyses that included oxidative stress biomarkers ( $\mathrm{NO}$ and $\mathrm{H}_{2} \mathrm{O}_{2}$ ), enzymatic antioxidant (SOD), cholinergic markers acetylcholine esterase (ACHE), acetylcholine (ACH),neurotransmitters dopamine, adrenaline (AD) and noradrenaline (NA), The second portion of the brain was fixed in $10 \%$ formalin for histological investigation.

\section{Biochemical analyses \\ Oxidative stress biomarkers}

Brain nitric oxide (NO) level was assayed by the spectrophotometric method according to Berkels et al. [15]. Brain hydrogen peroxide $\left(\mathrm{H}_{2} \mathrm{O}_{2}\right)$ level was determined by the spectrophotometric method according to Aebi [16].

\section{Antioxidant enzymes activity}

Brain superoxide dismutase (SOD) activity was determined colorimetrically according to the method of Nishikimietal [17]. Brain ACHE was determined colorimetrically according to the method of Den Blaauwen et al. [18]. Brain ACH level was measured calorimetrically according to the method of Oswald et al. [19]. The assay method is based on oxidation of free choline to betaine via the intermediate betaine aldehyde. The reaction generates products which can be measured at $570 \mathrm{~nm}$.

\section{Brain catecholamine (NA, $A D$, and $D A)$}

Frozen brain samples were homogenised in $30 \mathrm{ml}$ butanol for catecholamine extraction as described by Brownlee and Springgs. 25 This extraction was then transferred to a $125 \mathrm{ml}$ bottle and $2 \mathrm{ml}$ of $0.01 \mathrm{~N} \mathrm{HCI}$ and $5 \mathrm{~g}$ sodium chloride were added. The bottle was then shaken at room temperature with a speed of 50 strokes per minute for one hour. The mixture was then centrifuged at $2000 \mathrm{rpm}$ for 5 min. After extraction, the fluorimetric technique was used for estimation of neurotransmitters (NA, AD and, DA) levels at excitation and emission wavelength on spectrophotometer as described by Ciarlone [20].

\section{Hypothalamus pituitary-adrenal gland function}

ACTH and Cortisol are measured by radioimmunoassay measurements according to Talbot et al. [21] and Lindsay et al. [22].

\section{Histopathological examination}

The brain tissue was fixed in $10 \%$ formalin for one week, washed in running tap water for $24 \mathrm{~h}$ and dehydrated in ascending series of ethanol (50-90 \%), followed by absolute alcohol. The samples were cleared in xylene and immersed in a mixture of xylene and paraffin at $60^{\circ} \mathrm{C}$. The tissue was then transferred to pure paraffin wax of the melting point $58^{\circ} \mathrm{C}$ and then mounted in blocks and left at $4{ }^{\circ} \mathrm{C}$. The 
paraffin blocks were sectioned on a microtome at a thickness of 5 $\mu \mathrm{m}$ and mounted on clean glass slides and left in the oven at $40^{\circ} \mathrm{C}$ to dryness. The slides were de-paraffinized in xylene and then immersed in descending series of ethanol (90-50\%). The ordinary haematoxylin and eosin ( $\mathrm{H}$ and $\mathrm{E}$ ) stain was used to stain the slides [23].

\section{Statistical analyses}

Statistical analysis is carried out using SPSS computer program (version 8) combined with Co-State computer program, where unshared letters are significant at $p \leq 0.05$.

\section{RESULTS}

Acetylcholine level and acetylcholine esterase activity in different experimental groups

Table (1): demonstrated the insignificant difference between normal control and treated control with $H$. pluvialis extract. AD induced rats showed a significant decrease in Ach with percent 37.19\%. While a significant increase in AchE with percent $64.91 \%$. Treatment of AD rats with $H$. pluvialis extract declared a significant increase in Ach, while a significant reduction in AchE with the percent of improvement 19.14 and $44.03 \%$, respectively comparing with rivastigmine anti-Alzheimer drug which revealed improvement percentages 21.86 and $53.10 \%$, respectively.

\section{Catecholamine levels in different experimental groups}

Table (2): showed an insignificant change in normal control rats treated with $H$. pluvialis as compared to normal control untreated rats. $\mathrm{AD}$ induced rats exhibited a significant reduction in $\mathrm{DA}, \mathrm{NA}$ and $\mathrm{AD}$ levels in $\mathrm{AD}$ induced rats with reduction percent $40.44,50.35$ and $47.43 \%$, respectively. Treatment of $\mathrm{AD}$ induced rats with $\mathrm{H}$. pluvialis showed improvement in DA, NA and AD levels with percentages 20.59, 33.31 and $25.43 \%$ respectively, compared to a standard drug which revealed improvement with percentage 25.73, 40.34 and 34.02\%, respectively.

Antioxidant enzyme and oxidative stress biomarkers levels in different experimental groups

Table (3): recorded the insignificant change in SOD activity, $\mathrm{H}_{2} \mathrm{O}_{2}$ and NO levels in normal rats treated with $H$. pluvialis as compared to untreated control rats. AD induced rats showed a significant reduction in SOD activity (57.59\%), while a significant increase in NO (157.80\%) and $\mathrm{H}_{2} \mathrm{O}_{2}$ (235.56\%) levels was demonstrated. Treatment of AD induced rats with H. pluvialis recorded amelioration percent in SOD activity, $\mathrm{H}_{2} \mathrm{O}_{2}$ and $\mathrm{NO}$ levels $30.00,159.11$ and $128.57 \%$, respectively comparing to standard drug $34.48,191.11$ and $146.00 \%$, respectively.

\section{ACTH and cortisol levels in different experimental groups}

The insignificant change was recorded in ACTH and CORT levels in normally treated rats with $H$. pluvialis. While a significant increase in ACTH and CORT levels was detected in AD induced rats with percentage increase 144.03 and $107.08 \%$, as compared to normal control rats. Treatment of $\mathrm{AD}$ induced rats with $H$. pluvialis showed amelioration percent in ACTH and CORT levels 118.66 and $92.61 \%$ respectively (table 4).

\section{Histopathological examination}

Microscopically, cerebral cortex of control, untreated rats revealed no histopathological changesas compared to normal control rats (Photomicrographs 1). Also, the cerabral cortex of treated rats with H. Pluvialis showed no histopathological changes(Photomicrographs $2,3)$ comparing to normal control rats. Meanwhile, cerebral cortex of rat treated with $\mathrm{Al}$ showed congestion of cerebral blood vessel (Photomicrograph 4), necrosis of neurons (Photomicrograph. 5) and multifocal cerebral haemorrhage (Photomicrograph 6). Examined sections from rats treated with rivastigmine revealed neuronophagia of sporadic necrotic neurons (Photomicrograph 7) and necrosis of some neurons (Photomicrographs 8).

Some examined sections from rats treated with $H$. Pluvialis extract showed no histopathological changes (Photomicrograph 9), whereas, other sections revealed necrosis of neurons (Photomicrograph 10). In addition, the hippocampus of control, untreated rat revealed no histopathological changes (Photomicrographs 11 and 12). However, the hippocampus of rat treated with $\mathrm{Al}$ showed necrosis of pyramidal cells Photomicrograph. 13). Some examined sections from a rat treated with rivastigmine showed no histopathological changes (Photomicrograph14), whereas, other sections from this group revealed necrosis of some pyramidal cells (Photomicrograph 15).

Table 1: Acetylcholine andacetylcholine esterase levels in different experimental groups

\begin{tabular}{lll}
\hline Groups/Parameters & Ach (u mole/mg protein) & AChE (U/mg protein) \\
\hline Normal control & $89.87 \pm 2.56^{\mathrm{a}}$ & $540.22 \pm 11.20^{\mathrm{a}}$ \\
H. pluvialis treated normal control & $92.00 \pm 5.10^{\mathrm{a}}$ & $544.12 \pm 13.21^{\mathrm{a}}$ \\
\%Change & 2.370 & 0.72 \\
AD & $56.45 \pm 2.56^{\mathrm{b}}$ & $890.86 \pm 23.20^{\mathrm{b}}$ \\
\%Change & 37.19 & 64.91 \\
H. pluvialis treated AD rats & $73.65 \pm 4.21^{\mathrm{c}}$ & $653.00 \pm 12.90^{\mathrm{c}}$ \\
\%Change & 18.04 & 20.88 \\
\% Improvement & 19.14 & 44.03 \\
Standard Drug-treated AD rats & $76.10 \pm 4.50^{\mathrm{c}}$ & $604.00 \pm 11.20^{\mathrm{c}}$ \\
\%Change & 15.32 & 11.81 \\
\%Improvement & 21.86 & 53.10 \\
\hline
\end{tabular}

Data are means $\pm S D$ of ten rats in each group. Unshared letters between groups are the significance value at $p \leq 0.05$.

Table 2: Catecholamine levels in different experimental groups

\begin{tabular}{|c|c|c|c|}
\hline Groups/Parameters & DA(ng/gm brain tissue) & NA (ng/gm brain tissue) & AD (ng/gm brain tissue)) \\
\hline Normal control & $66.00 \pm 819^{\text {ef }}$ & $198.90 \pm 13.10^{\mathrm{b}}$ & $300.12 \pm 5.10^{\mathrm{e}}$ \\
\hline H. pluvialis treated normal control & 67. $19 \pm 7.20^{\mathrm{ef}}$ & $200.55 \pm 9.15^{b}$ & $278.80 \pm 3.30^{\mathrm{e}}$ \\
\hline \%Change & 1.80 & 0.83 & 7.10 \\
\hline $\mathrm{AD}$ & $39.31 \pm 6.12^{\mathrm{b}}$ & $98.76 \pm 3.63^{b}$ & $157.78 \pm 13.12^{b}$ \\
\hline \%Change & 40.44 & 50.35 & 47.43 \\
\hline H. pluvialis treated $\mathrm{AD}$ rats & $52.90 \pm 5.03^{\mathrm{c}}$ & $165.02 \pm 6.21^{\mathrm{c}}$ & $234.10 \pm 12.10^{c}$ \\
\hline \%Change & 19.85 & 17.03 & 21.99 \\
\hline \% Improvement & 20.59 & 33.31 & 25.43 \\
\hline Standard Drug treated AD rats & 56. $29 \pm 3.62^{c}$ & $179.0 \pm 5.07^{b}$ & $2.59 .89 \pm 6.29^{c}$ \\
\hline \%Change & 14.71 & 10.00 & 13.40 \\
\hline$\%$ Improvement & 25.73 & 40.34 & 34.02 \\
\hline
\end{tabular}

Data are means \pm SD of ten rats in each group. Unshared letters between groups are the significance value at $p \leq 0.05$. 
Moreover, some examined sections from rats treated with $H$. Pluvialis extract showed necrosis of some pyramidal cells (Photomicrograph 16), whereas, other sections from this group revealed no histopathological changes (Photomicrograph 17). The lesion score in different experimental groups are demonstrated in the table (5), which declared a mild change in necrosis of neuron and pyramidal cells of hippocampus while the absence of cerebral haemorrhage and neuronophagia as a result of treatment of neurotoxic rats with either $H$. pluvialis or standard drug.

Table 3: Antioxidant enzyme and oxidative stress biomarker levels in different experimental groups

\begin{tabular}{llll}
\hline Groups/Parameters & SOD $(\mathbf{U} / \mathbf{m g}$ protein) & $\mathbf{H}_{2} \mathbf{O}_{2}(\boldsymbol{\mu m o l} / \mathbf{m g}$ protein) & NO $(\boldsymbol{\mu m o l} \backslash \mathbf{m g}$ protein) \\
\hline Normal control & $2.90 \pm 0.11 \mathrm{a}$ & $9.00 \pm 0.50^{\mathrm{a}}$ & $35.00 \pm 2.10^{\mathrm{a}}$ \\
H. pluvialis treated normal control & $2.99 \pm 0.30^{\mathrm{a}}$ & $8.10 \pm 0.27^{\mathrm{a}}$ & $33.10 \pm 1.09^{\mathrm{a}}$ \\
\%Change & 3.10 & 10.00 & 5.43 \\
AD & $1.23 \pm 0.12^{\mathrm{b}}$ & $30.20 \pm 1.10^{\mathrm{b}}$ & $90.23 \pm 8.32^{\mathrm{b}}$ \\
\%Change & 57.59 & 235.56 & {$[15]^{7 \cdot[80]}$} \\
H. pluvialis treated AD rats & $2.10 . \pm 0.10^{\mathrm{c}}$ & $15.88 \pm 1.90^{\mathrm{c}}$ & $45.23 \pm 2.50^{\mathrm{c}}$ \\
\%Change & 27.58 & 76.44 & 29.22 \\
\% Improvement & 30.00 & 159.11 & 128.57 \\
Standard Drug-treated AD rats & $2.23 \pm 0.23^{\mathrm{C}}$ & $13.00 \pm 1.00^{\mathrm{c}}$ & $39.13 \pm 4.00^{\mathrm{c}}$ \\
\%Change & 23.10 & 44.44 & 11.80 \\
\% Improvement & 34.48 & 191.11 & 146.00 \\
\hline
\end{tabular}

Data are means \pm SD of ten rats in each group. Unshared letters between groups are the significance value at $p \leq 0.05$.

Table 4: ACTH and cortisol levels in different experimental groups

\begin{tabular}{lll}
\hline Groups/Parameters & ACTH(pg/mg protein) & CORT (ug/mg protein) \\
\hline Normal control & $26.80 \pm 1.56^{\mathrm{a}}$ & $19.22 \pm 1.23^{\mathrm{a}}$ \\
H. pluvialis treated normal control & $25.00 \pm 2.19^{\mathrm{a}}$ & $15.12 \pm 1.29^{\mathrm{a}}$ \\
\%CHANGE & 6.72 & 21.33 \\
AD & $65.40 \pm 6.50^{\mathrm{b}}$ & $39.80 \pm 3.21^{\mathrm{b}}$ \\
\%CHANGE & 144.03 & 107.08 \\
H. pluvialistreated AD rats & $33.60 \pm 3.25^{\mathrm{c}}$ & $22.00 \pm 1.21^{\mathrm{c}}$ \\
\%Change & 25.37 & 14.46 \\
\% Improvement & 118.66 & 92.61 \\
Standard Drug-treated AD rats & $36.00 \pm 2.30^{\mathrm{c}}$ & $19.00 \pm 11.20^{\mathrm{a}}$ \\
\% Imphange & 34.33 & 1.14 \\
\end{tabular}

Data are means \pm SD of ten rats in each group. Unshared letters between groups are the significance value at $p \leq 0.05$.

Table 5: Histopathological lesions score in different experimental groups

\begin{tabular}{|c|c|c|c|c|}
\hline Histopathological lesion & Group 1 & Group 2 & Group 3 & Group 4 \\
\hline Necrosis of neurons & - & +++ & + & + \\
\hline Neuronophagia & - & ++ & - & - \\
\hline Cerebral haemorrhage & - & +++ & - & - \\
\hline Necrosis of pyramidal cells of hippocampus & - & ++ & + & + \\
\hline
\end{tabular}

$(-)$ no change $(+)$ mild change $(++)$ moderate change $(+++)$ severe change

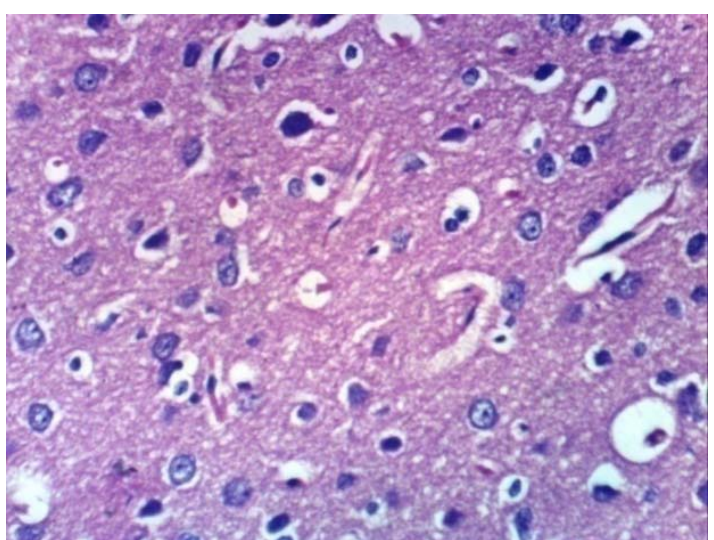

Photomicrograph 1: Cerebral cortex of normal control, rat showing histopathological changes ( $\mathrm{H}$ and $\mathrm{E} X \mathrm{400}$ )

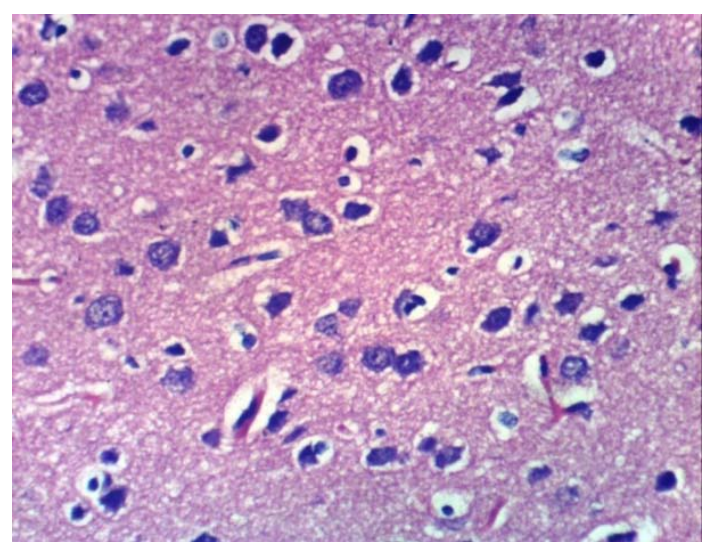

Photomicrograph 2: Cerebral cortex of normal control rats treated with H. Pluvialis showing no histopathological changes (H and E X 400) 


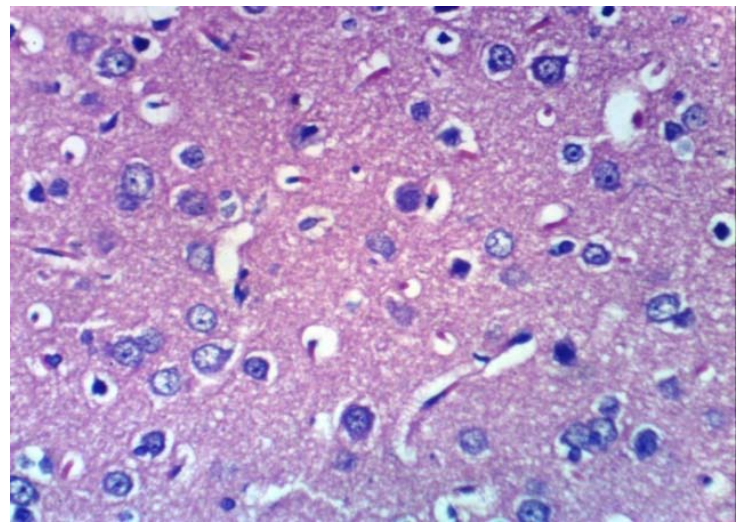

Photomicrograph 3: Cerebral cortex of normal control rats treated with $H$. pluvialis showing no histopathological changes ( $H$ and E X 400)

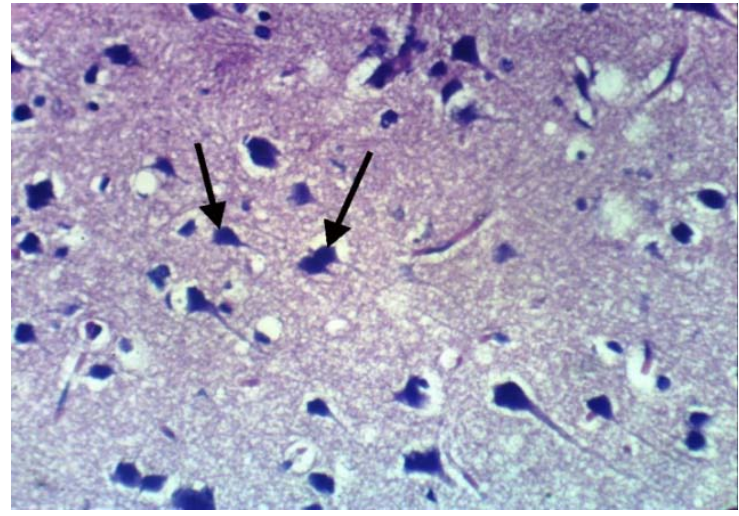

Photomicrograph 5: Cerebral cortex of rat treated with Al showing necrosis of neurons ( $H$ and $E X$ 400)

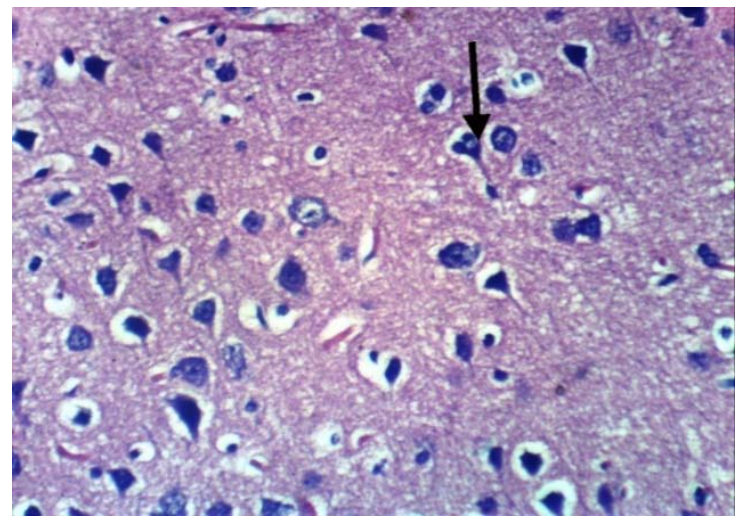

Photomicrograph 7: Cerebral cortex of rat treated with rivastigmine showing neuronophagia of sporadic necrotic neurons ( $H$ and E X 400)

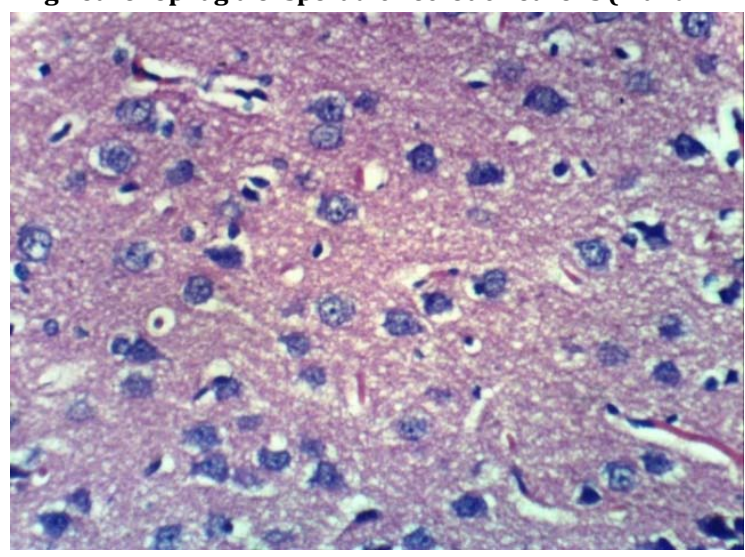

Photomicrograph 9: Cerebral cortex of rat treated with $H$. pluvialis showing no histopathological changes ( $\mathrm{H}$ and $\mathrm{E} X \mathrm{400}$ )

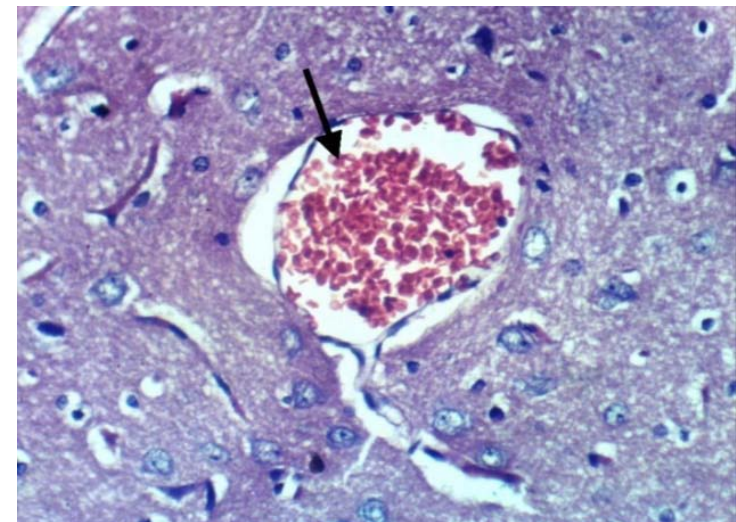

Photomicrograph 4: Cerebral cortex of rat treated with Al showing congestion of cerebral blood vessel ( $H$ and $E X$ 400)

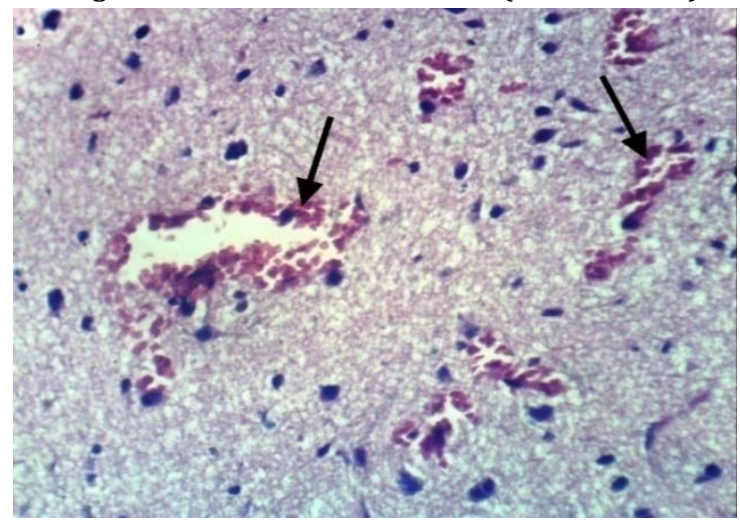

Photomicrograph 6: Cerebral cortex of rat treated with Al showing multifocal cerebral haemorrhage ( $H$ and $E X 400)$

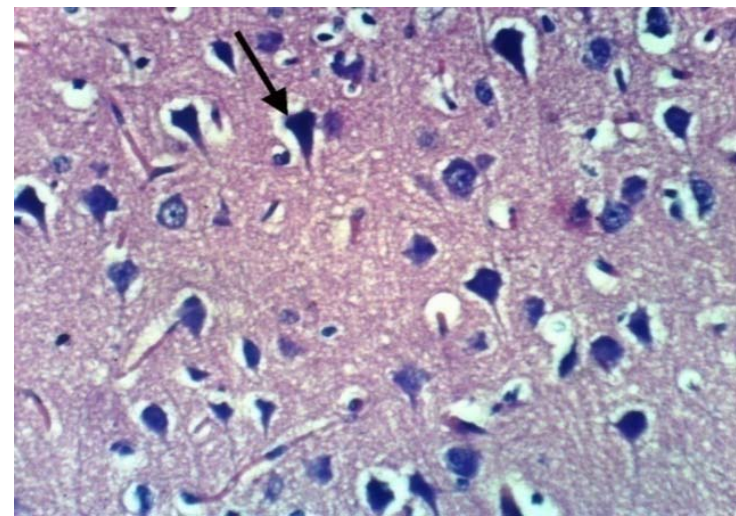

Photomicrograph 8: Cerebral cortex of rat treated with rivastigmine showing necrosis of some neurons (H and E X 400)

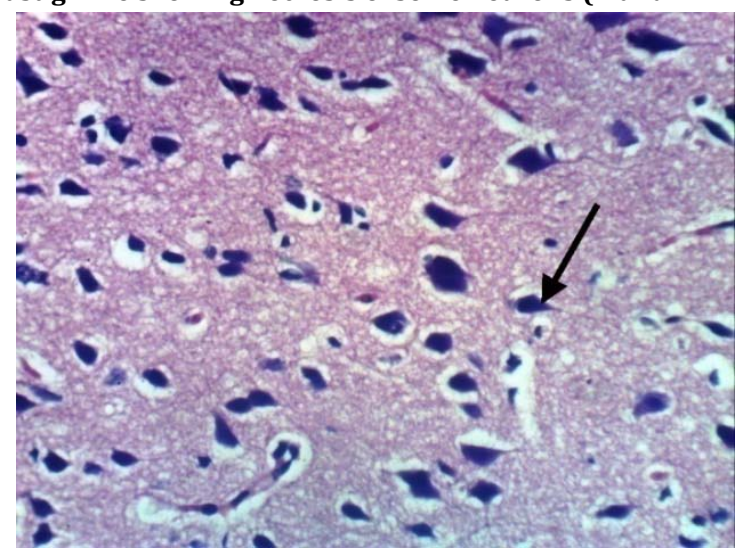

Photomicrograph 10: Cerebral cortex of rat treated with $\boldsymbol{H}$. pluvialis showing necrosis of neurons (H and E X 400) 


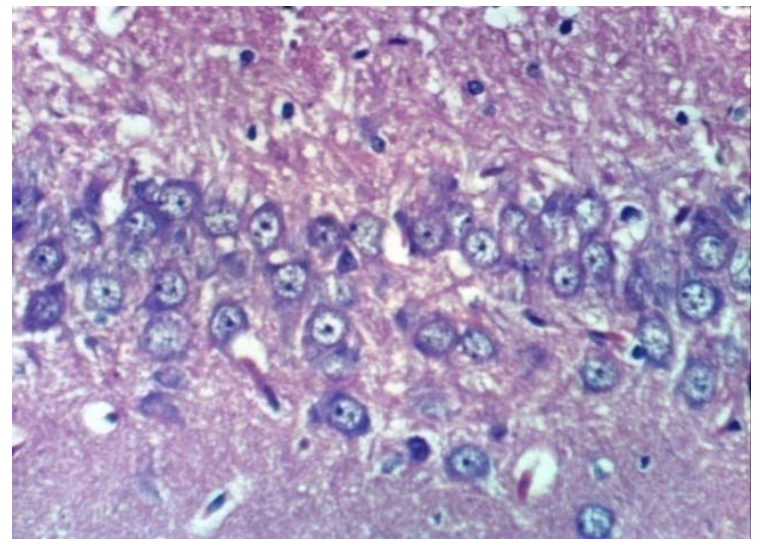

Photomicrograph 11: Hippocampus of normal control rats showing no histopathological changes ( $H$ and $E X 400)$

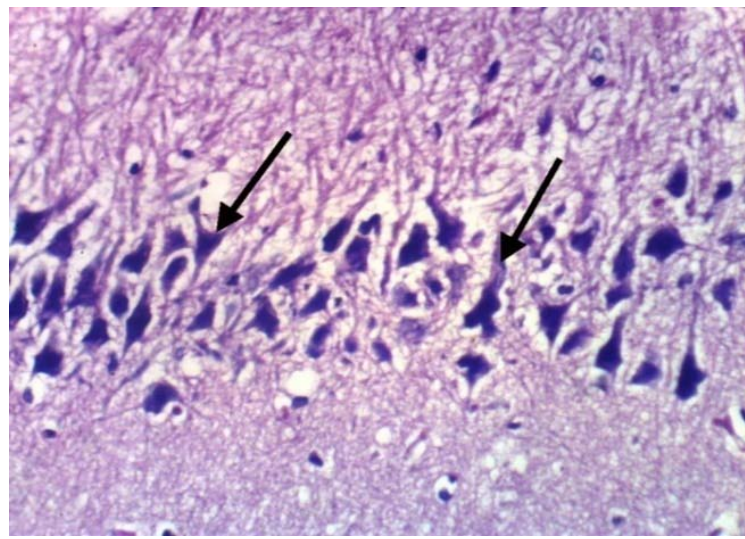

Photomicrograph 13: Hippocampus of rat treated with AL showing necrosis of pyramidal cells ( $H$ and $E X 400$ )

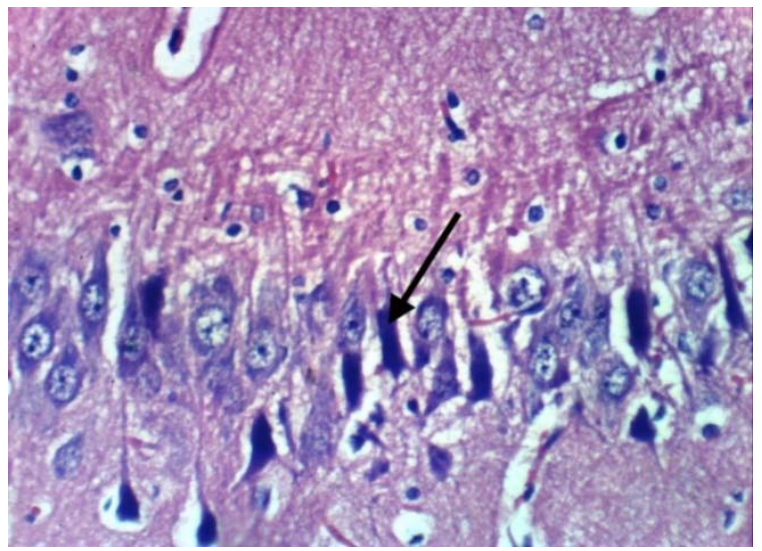

Photomicrograph 15: Hippocampus of rat treated with rivastigmine showing necrosis of some pyramidal cells ( $H$ and E X 400)

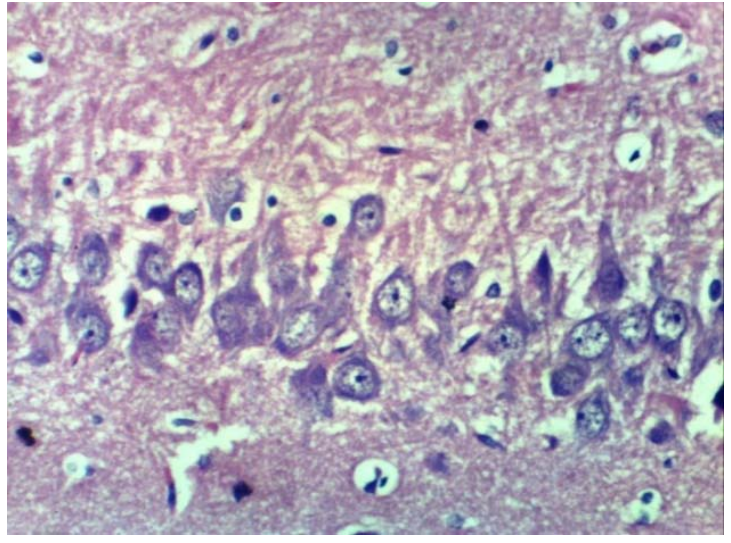

Photomicrograph 12: Hippocampus of normal control rats treated with $H$. Pluvialis showing no histopathological changes (H and E X 400)

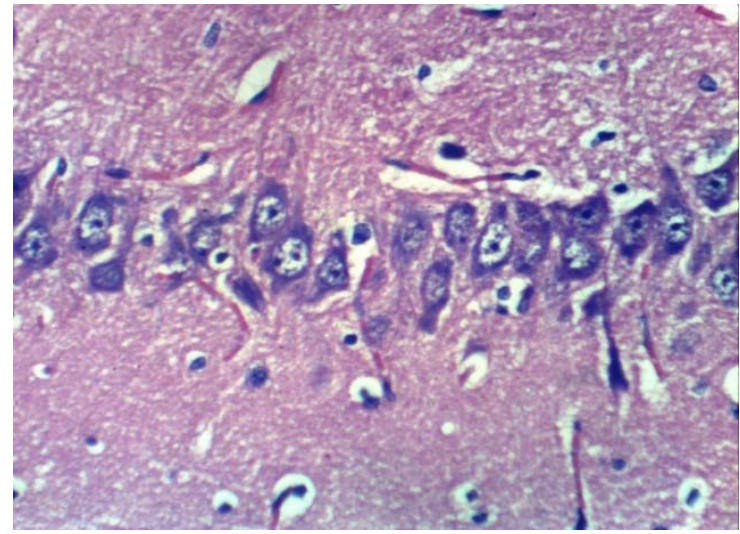

Photomicrograph 14: Hippocampus of rat treated with rivastigmine showing no histopathological changes ( $\mathrm{H}$ and E X 400)

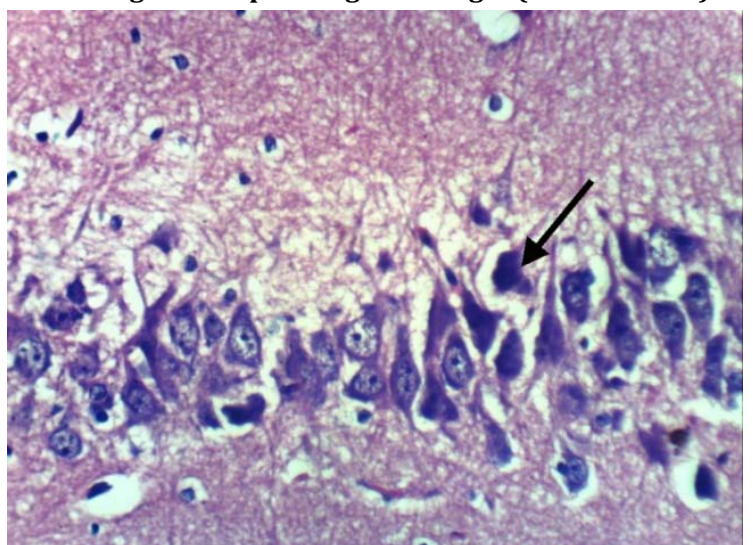

Photomicrograph 16: Hippocampus of rat treated with $\mathrm{H}$. pluvialis extract showing necrosis of some pyramidal cells (H and E X 400)

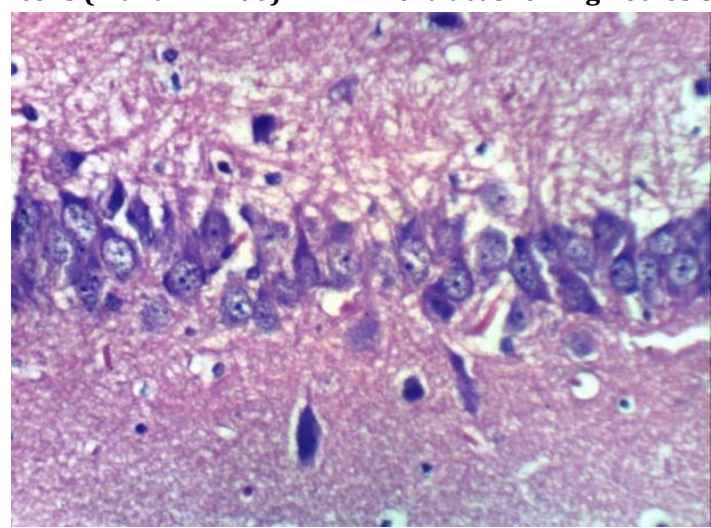

Photomicrograph 17: Hippocampus of rat treated with $H$. pluvialis showing no histopathological changes (H and E X 400) 


\section{DISCUSSION}

The present findings revealed that $\mathrm{AlCl}_{3}$ administration is induced a significant elevation in serum AchE activity. These results may be attributed to the allosteric interaction between $\mathrm{Al}$ and the peripheral anionic site of enzyme molecule to modify the secondary structure and eventually its activity $[1,24,25]$. Treatment of AD-induced rats with rivastigmine produced a significant decline in AchE activity. These results are in agreement with those of Liang and Tang [26]. Rivastigmine is a novel AchE inhibitor that displays specific activity for central AchE over peripheral AchE [1] by interacting with the esteratic site in ChE molecules [1].

The present results also declared that Ach is significantly decreased in $\mathrm{AD}$ induced rats. This observation may be explained on the basis of; mitochondrial dysfunction is a prominent and primary feature of AD [27]. Dysfunctional mitochondria cause high levels of ROS that may be noxious for neurons [28]. Moreover, ROS treats mitochondria as a target triggering oxidation of its constituents such as DNA, lipids, and proteins which finally results in mitochondrial worsening [29]. Declined calcium uptake and increased calcium burden leads to calcium deregulation and enlarged intracellular calcium in the brain [30]. Furthermore, mitochondrial dysfunction has been reported to modify the levels of numerous enzymes which contain pyruvate dehydrogenase and $\alpha$-keto glutaratede hydrogenases, ATP-citrate lyase, and acetoacetyl-CoA thiolase. Reduced levels of these enzymes result in diminish production of acetyl-coA which causes deficit cholinergic expressions in $A D$ patients [31]. The selective insufficiency of acetylcholine in AD, results in dementia in $\mathrm{AD}$, has given rise to "cholinergic hypothesis," which recommends that a lack of acetylcholine is critical in the origin of the signs of $\mathrm{AD}$ [27].

The high activity of acetylcholine esterase, an enzyme that converts acetylcholine into inactive choline and acetate by aluminium has been found to increase AchE activity and accelerate the assembly of $\beta$-amyloid into fibrils as well as is responsible also for the detected low level of acetylcholine in brain tissue [32].

In addition, the current results showed a significant decrease in catecholamine level in $\mathrm{AD}$ induced rats as compared to normal control one. In agreement with the present study Murray and Duong (33) declared that there has been an interaction between catecholamine and pathological amyloid proteins in neurodegenerative diseases. The reduced level of noradrenaline in $\mathrm{AD}$ induced rats may be due to degeneration of NA producing centers in the brain stem (locus ceruleus, LC) [33]. This suggests that NA potentiates $A \beta$ toxicity. In addition, Sawada et al. [34], hypothesised that dopamine is depleted by $60-70 \%$, due to dopaminergic neuronal degeneration. So, it has been suggested that oxidative stress-induced degeneration in adrenergic neurons is the main cause of down-regulation of adrenaline level in the brain of $\mathrm{Al}$ challenged rats as shown in the present results.

Further, the present results demonstrated, signification elevation in oxidative stress biomarkers, $\mathrm{NO}$ and $\mathrm{H}_{2} \mathrm{O}_{2}$. levels combined with a significant decrease in antioxidant enzyme activity,SOD. It's well known that the process of aging is connected with augmented oxidative stress [27]. It has been reported that oxidative stress plays a vital role in the pathogenesis of $\mathrm{AD}$ leading to neuronal dysfunction and cell loss [35]. As $\mathrm{NO}, \mathrm{H}_{2} \mathrm{O}_{2}$. Productions are significantly augmented in $\mathrm{AD}$ induced rats [27]. It has been reported that an increase of oxidative biomolecule products and reduction in antioxidant levels or antioxidant enzyme action such as SOD leads to AD [27]. The decreased plasma levels of antioxidants such as albumin, bilirubin, uric acid, lycopene, vitamin A, vitamin C, and vitamin $\mathrm{E}$ has been reported in $\mathrm{AD}$ patients [36].

Moreover, a significant increase was detected in ACTH and cortisol levels in AD induced rats. This may be due to the hypothalamus-pituitary-adrenal gland (HPA) axis respond to stress due to Al exposure by increasing the secretion of a corticotropin-releasing hormone in the hypothalamus, adrenocorticotropic hormone (ACTH) in the anterior pituitary gland, as well as adrenal corticosteroids and cortisol in the adrenal gland. The activation of HPA may contribute to the pathogenesis of Alzheimer disease. The elevation in cortisol and ACTH may relate to cortisol neurotoxicity hypnosis leading to the pathogenesis of Alzheimer's disease [7, 37, 38].

Histopathological investigation of cerebellum and hippocampus of $\mathrm{AD}$ rats in the present results revealed necrosis of neurons and multifocal cerebral haemorrhage in addition to necrosis of pyramidal cells. While $\mathrm{AD}$ rats treated with neuronophagia of sporadic necrotic neurons and necrosis in the cerebellum as well as some necrotic pyramidal cells In accordance with the present results Salem et al. [1], showed severe congestion in the blood vessels with oedema in the meninges of AD-induced rats. While a micrograph of a brain section of $\mathrm{AD}$-induced rats treated with rivastigmine showing no histopathological alteration in the hippocampus. These results are in agreement with the results of Bihaqia et al. [39], who showed the normal histological appearance of the brain cells treated with rivastigmine tartrate and revealed that rivastigmine reversed histopathological alterations caused by $\mathrm{Al}$.

On the other hand, treatment of AD-induced rats with $H$. Pluvialis extract showed no histopathological changes in the cerebellum, whereas, other sections revealed necrosis of neurons. However no histopathological alteration was detected in the hippocampus of $H$. pluvialis extract treated $\mathrm{AD}$ rats, which may be contributed to, in $\mathrm{AD}$ induced rats ROS interact with nitric oxide (NO) to form peroxynitrite (ONOO-), a highly toxic compound. The bioavailability of endothelial NO is then reduced, and its vasoprotective effect is disrupted [40]. However, treatment with $H$. pluvialis containing antioxidant molecules, especially carotenoids, which play an important role in the control of the oxidative process. These antioxidant molecules (carotenoids) possess a strong antioxidant power due to their double-bonded structure, allowing the delocalization of impaired electrons, reducing oxidative damage and hence tissue architectures [2].

Further, treatment of AD-induced rats with $H$. pluvialis extract caused significant depletion in brain and serum AchE activity. Acetylcholine esterase inhibitor activity of $H$. pluvialis extract is probably contributed to the therapeutic potential of the natural extract astaxanthin and its esters in vascular cell protection against oxidative stress, which could be exploited in prevention and/or treatment of cardiovascular as well as neurological diseases [9]. The same authors added that esters of astaxanthin displayed stronger antioxidant activities than free astaxanthin which may have antiacetylcholine esterase and anti-butyrylcholinesterase activity, anticancer, antidiabetic and anti-inflammatory agent [41].

Besides, $H$. pluvialis extract contains active constitutes which have the capacity of scavenging free radicals and to modulate the expression of genes encoding antioxidant enzymes such as oestrogens, growth factors and vitamin E[41]. The neuroamelorative effect of $H$. pluvialis extract in the present results is in accordance with Chang et al. [42] and Guerra et al. [43] who studied the antioxidant and neuroprotective effect of $H$. pluvialis and concluded that, treatment with astaxanthin was able to partially reduce intracellular ROS production and restore the phagocytic capacity of human neutrophils. Thus, all of these results assert that natural astaxanthin plays a protective role in cells exposed to oxidative stress which could inhibit $A \beta$-induced cytotoxicity and reactive oxygen species production in brain cells. So, astaxanthin and its esters are the promising active constitutes in $H$. puvialis, which have a neuroprotective capacity to antagonize $A \beta$-induced cytotoxicity in the nerve cells.

\section{CONCLUSION}

In conclusion, the current study revealed that treatment of ADinduced rats with $H$. pluvialis extract significantly ameliorates the cholinergic dysfunction, catecholamine levels, oxidative stress, antioxidant enzyme and HPA hormones-induced neurodegeneration characterising Alzheimer's disease. These effects were achieved through the powerful anti-oxidant activity of $H$. pluvialis astaxanthin. Noteworthy, $H$. pluvialis extract revealed the more pronounced promising effect on most of the measured biochemical parameters as well as a histological feature of the brain more or less similar to the anti-Alzheimer drug rivastigmine. The selected alga extract may 
represent good therapeutic approaches for the intervention of the progressive neurological damage associated with Alzheimer's disease with special reference to the antioxidant and hypothalamuspituitary-adrenal insults.

\section{ACKNOWLEDGMENT}

This work was supported and funded by the project entitled "Biodiesel production from algae as a renewable energy source". Funding organisation: Research Development and Innovation program (RDI), Funding Program: EU-Egypt Innovation Fund, 2014-2017.

\section{CONFLICT OF INTERESTS}

\section{Declared none}

\section{REFERENCES}

1. Panche A, Chandra S, Diwan Ad, Harke S. Alzheimer's and current therapeutics: a review. Asian J Pharm Clin Res 2015;8:14-9.

2. Azam F, Amer AM, Abulifa AR, Elzwawi MM. Ginger components as new leads for the design and development of novel multi-targeted anti-Alzheimer's drugs: a computational investigation. Drug Des Dev Ther 2014;8:2045-59.

3. Pamulaparthi A, Prathap VR, Banala M, Nanna RS. Experimental evaluation of antidepressant and antianxiety activities of aqueous leaf extracts of Senna Alata (L.) Roxb. Using in vitro animal models. Int J Curr Pharm Res 2016;8:60-3.

4. Pavandi M, Messripour M, Moshtaghi AA. Effect of Aluminium and Copper on dopamine synthesis in striatal synaptosomes of rat's Brain. Bull Env Pharmacol Life Sci 2014;3:12-6.

5. Breydo L, Uversky VN. The role of metal ions in the aggregation of intrinsically disordered proteins in neurodegenerative diseases. Metallomics 2011;3:1163-80.

6. Sapolsky RM, Pulsinelli W. Glucocorticoids potentiate ischemic injury to neurons: therapeutic implications. Science 1985;229:1397.

7. Franceschi M, Airaghi L, Gramigna C, Truci G, Manfredi MG, Canal $\mathrm{N}$, et al. ACTH and cortisol secretion in patients with Alzheimer's disease. J Neurol Neurosurg Psychiatry 1991; 54:836-37.

8. Bowen J, Soutar C, Serwata R, Lagocki S, White D, Davies S, et al. Utilization of (3S, 3. S)-astaxanthin acyl esters in pigmentation of rainbow trout (Oncorhynchusmykiss). Aquacult Nutr 2002;8:59-68.

9. Régnier P, Bastias J, Rodriguez-Ruiz V, Caballero-Casero N, Caballo C, Sicilia D, et al. Astaxanthin from Haematococcuspluvialis prevents oxidative stress on human endothelial cells without toxicity. Mar Drugs 2015;13:2857-74.

10. Spiler GE, Dewell A. Safety of an astaxanthin-rich Haematococcusspluvialis algal extract: a randomised clinical trial. J Med Food 2003;1:53-6.

11. Liang H, Ma A, Zhang P, Bi SL, Shi DY. Effect of ethanol extract of alga Laurencia supplementation on DNA oxidation and alkylation damage in mice. Asia Pac J Clin Nutr 2007;16:164-8.

12. Kumar V, Bal A, Gill KD. Aluminum-induced oxidative DNA damage recognition and cell cycle disruption in different regions of rat brain. Toxicology 2009;264:137-44.

13. Corey-Bloom J, Anand R, Veach J. for the ENA 713 B352 study group a randomised trial evaluating the efficacy and safety of ENA 713 (rivastigmine tartrate), a new acetylcholine esterase inhibitor, in patients with mild to moderately severe Alzheimer's disease. Int J Geriatr Psychopharmacol 1998;1:55-65.

14. El-Baz FK, Khalil WKB, Booles HF, Aly HF, Ali GH. Dunaliella salina suppresses oxidative stress, alterations in the expression of pro-apoptosis and inflammation-related genes induced by STZ in diabetic rats. Int J Pharm Sci Rev Res 2016;38:219-26.

15. Berkels R, Purol-Schnabel S, Roesen R. Measurement of nitric oxide by reconversion of nitrate/nitrite to nitric oxide. Methods Mol Biol 2004;279:1-8.

16. Aebi H. Catalase in vitro. Methods Enzymol 1984;105:121-6.

17. Nishikimi M, Appaji N, Yagi K. The occurrence of superoxide anion in the reaction of reduced phenazine methosulfate and molecular oxygen. Biochem Biophys Res Commun 1972;46:849-54.
18. Den Blaauwen DH, Poppe WA, Tritschler W. Acetylcholinesterase with acetylthiocholine iodide as substrate: references depending on age and sex with special reference to hormonal effects and pregnancy. J Clin Chem Clin Biochem 1983;21:381-6.

19. Oswald C, Smits SH, Hoing M, Sohn-Bosser L, Dupont L, Le Rudulier D, et al. Crystal structures of choline/acetylcholine substrate-binding protein chox from sinorhizobiummeliloti in the liganded and unliganded-closed states. J Biol Chem 2008;283:32848-59.

20. Ciarlone AF. Further modification of a fluorometric method for analyzing brain amines. Microchem J 1978;23:9-12.

21. Talbot JA, Kane JW, White A. Analytical and clinical aspects of adrenocorticotrophin determination. Ann Clin Biochem 2003;40:453.

22. Lindsay JR, Shanmugam VK, Oldfield EH. A comparison of immunometric and radioimmunoassay measurement of ACTH for the differential diagnosis of Cushing's syndrome. J Endocrinol Invest 2006;29:983.

23. Drury RA, Wallington EA. Carleton's histology technique. $4^{\text {th }}$ edn. New York: Oxford University Press; 1980. p. 653-61.

24. Kumar A, Dogra S, Prakash A. Protective effect of curcumin (Curcuma longa), against aluminum toxicity: possible behavioural and biochemical alterations in rats. Behav Brain Res 2009;205:384-90.

25. Aly HF, Metwally FMM, Hanaa H, Ahmed HH. Neuroprotective effects of dehydroepiandrosterone (DHEA) in rat model of Alzheimer's disease. Acta Biochim Pol 2011;58 :513-20.

26. Liang YQ, Tang XC. Comparative effects of huperzine A, donepezil and rivastigmine on cortical acetylcholine level and acetylcholinesterase activity in rats. Neurosci Lett 2004;361:56-9.

27. Kaur K, Kaur R, Kaur M. Recent advances in alzheimer's disease: causes and treatment. Int J Pharm Pharm Sci 2016;8:8-15.

28. Moreira PI, Carvalho C, Zhu X, Smith MA, Perry G. Mitochondrial dysfunction is a trigger of Alzheimer's disease pathophysiology. Biochim Biophys Acta 2010;1802:2-10.

29. Hauptmann S, Scherping I, Drose S, Brandt U, Schulz KL, Jendrach M, et al. Mitochondrial dysfunction: an early event in Alzheimer pathology accumulates with age in AD transgenic mice. Neurobiol Aging 2009;30:1574-86.

30. Gibson GE, Chen HL, Xu H, Qiu L, Xu Z, Denton TT, et al. Deficits in the mitochondrial enzyme alpha-ketoglutarate dehydrogenase leads to Alzheimer's disease like calcium dysregulation. Neurobiol Aging 2012;33:1113-24.

31. Olichon A, Landes T, Arnaune-Pelloquin L, Emorine LJ, Mils V, Guichet A. Effects of OPA1 mutations on mitochondrial morphology and apoptosis: relevance to ADOA pathogenesis. J Cell Physiol 2007;211:423-30.

32. Ahmed HH, Zaazaa AM, Abd El-Motelp BA. Zingiberofficinale and Alzheimer's disease: evidence and mechanisms. Int J Pharm Sci Rev Res 2014;27:142-52.

33. Murray I, Duong K. Catecholamines and amyloid. Alzheimers Association 2011;7:S392-S393.

34. Sawada H, Oeda T, Yamamoto K. Catecholamines and neurodegeneration in Parkinson's disease from diagnostic marker to aggregations of $\alpha$-synuclein. Diagnostics 2013;3:210-21.

35. Jomova K, Vondrakova D, Lawson M, Valko M. Metals, oxidative stress and neurodegenerative disorders. Mol Cell Biochem 2010;345:91-104.

36. Kim TS, Pae CU, Yoon SJ, Lee NJ, Kim JJ, Lee SJ. Decreased plasma antioxidants in patients with Alzheimer's disease. Int J Geriatric Psychiatry 2006;21:344-8.

37. Swaab DF, Raadsheer FC, Endert E, Hofman MA, Kamphorst W, Ravid R. Increased cortisol levels in aging and Alzheimer's disease postmortem cerebrospinal fluid. J Neuroendocrinol 1994;6:681-7.

38. Stanier RY, Kunisawa MM, Cohn-Bazire G. Purification and properties of unicellular blue, green algae (order chroococcales). Bacteriol Rev 1971;35:171-201.

39. Bihaqia SW, Sharmab M, Singhc AP, Tiwari M. Neuroprotective role of convolvulus pluricaulison aluminium induced neurotoxicity in rat brain. J Ethnopharmacol 2009;124:409-15. 
40. Verma S, Szmitko PE. The vascular biology of peroxisome proliferator-activated receptors: modulation of atherosclerosis Can J Cardiol 2006;22:12B-17B.

41. Ambati RR, Phang SM, Ravi S, Aswathanarayana RG Astaxanthin: sources, extraction, stability, biological activities and its commercial applications a review. Mar Drugs 2014;12:128-52.

42. Chang CS, Chang CL, Lai GH. Reactive oxygen species scavenging activities in a chemiluminescence model and neuroprotection in rat pheochromocytoma cells by astaxanthin, $\beta$-carotene, and canthaxanthin. Kaohsiung J Med Sci 2013;29:412-21.
43. Guerra BA, Otton R, Impact of the carotenoid astaxanthin on phagocytic capacity, Hauptmann S, Scherping I, Drose S, et al. Mitochondrial dysfunction: an early event in Alzheimer pathology accumulates with age in $\mathrm{AD}$ transgenic mice. Neurobiol Aging 2009;30:1574-86.

\section{How to cite this article}

- $\quad$ Farouk K EL-Baz, Hanan F Aly, Gamila H Ali. Haematococcus pluvialis modulating effect on neurotransmitters, hormones and oxidative damage associated with Alzheimer'S disease in experimental rat's model. Int J Pharm Pharm Sci 2017; 9(2):198-206 